\title{
Frequency Analysis of the Tool with and without Wear during Turning by Modal Analysis
}

\author{
Aouad Razika* and Amara Idriss \\ Faculty of Technology Sciences, University of Brothers Mentouri Constantine, Algeria
}

\begin{abstract}
The stability of a cutting process directly influences the quality of a final surface. The control of the cutting process is an important problem for machining technology. Instabilities usually manifest as harmful chatter vibrations generated during cutting. Modal testing is a form of vibration testing which is able to determine the Frequency Response Function (FRF) of the mechanical test structures. In this context, we realized a study of vibration and of deformation between a tool without defect and a tool with two cases of defects. These defects have a random shape (any form), and the contact length tool-work piece, is considered the length of defects Lc=1 $\mathrm{mm}$ and the height of wear has been studied for two cases: $V B=0.1$ and $0.2 \mathrm{~mm}$. In this paper, the main focus is creating a predictive model based on vibrations of body mass. The body mass mean the amount of material that constituting the cutting tool. The loss of a part of this mass makes the tool lighter; it increases the vibration of the tool. In addition to that, the Finite Element Method (FEM) modal analysis was used to obtain the natural frequencies. In this analysis we use ANSYS software based on (FEM), it is known for its high performance, quality and ability to solve all kinds of challenging simulations. The main idea is to create defects (wear) on the flank surface in order to create a model prediction. After the creation of defects, we start the modal analysis to study the deformation and the frequency of the tool.
\end{abstract}

The results indicate that the frequency response and harmonic response analysis simulated by ANSYS with various defects created. First analysis is frequency response; we find the natural frequencies vary depending on the defect. When the tool is not defective we find the natural frequencies equal $337.77 \mathrm{~Hz}$ but in a tool with defects (VB=0.1-0.2 and $0.3 \mathrm{~mm}$ ) we find the natural frequencies equal $340.36 \mathrm{~Hz}, 340.69 \mathrm{~Hz}$ and $341.11 \mathrm{~Hz}$, this shows that the quality of the surface of the defect and its shape have an impact on the vibration of the tool. Then we based on a mathematical model to compare the results of the FEM where it shows a satisfactory correlation. In addition, the results of second analysis indicate that the deformation simulation by ANSYS with varying defects created. It increases with these defects: when $\mathrm{VB}=0.1 \mathrm{~mm}$, we find that the maximum normal elastic deformation equal 0.16344 $\mathrm{mm} / \mathrm{mm}$ and for $V B=0.2 \mathrm{~mm}$, we find that the maximum normal elastic deformation equal $0.16863 \mathrm{~mm} / \mathrm{mm}$, but for a new tool we find that the maximum normal elastic deformation equal $0.014976 \mathrm{~mm} / \mathrm{mm}$.

This paper is designed to be beneficial for researcher's engineers in manufacturing area In order to provide an advance vision about the vibration and the deformation evolution of the cutting tools when there are defects (wear) at tool tip.

Keywords: Modal analysis; Frequency response function; Finite element method; Deformation; Wear; Flank wear

\section{Introduction}

It is in a high demand to automatically monitor and diagnose tool wear, tool fault, or tool damage during machining process to increase efficiency and product quality and reduce production cost. The flank wear (VB) is investigated as the system fault [1]. The tool wear, especially the flank wear, is one of the most important aspects that affect lifespan and product quality in machining (Figure 1) [2,3].

In turning operations the cutting tool is subjected to a dynamic excitation due to the deformation of work material during the cutting operation. The relative dynamic motion between the cutting tool and the work piece will affect the result of the machining, in particular the surface finish. Thus vibration related problems are of great interest in turning operations. Thus, the vibration problem in metal cutting has a considerable influence on important factors such as productivity, production costs, etc. A thorough investigation of the vibrations involved is therefore an important step in challenging this problem [4]. To study this vibration, we use the modal analysis.

Modal analysis is a technique to study the dynamic characteristics of a structure under vibrational excitation. Natural frequencies, mode shapes and mode vectors of a structure can be determined using modal analysis. Modal analysis allows the design to avoid resonant vibrations or to vibrate at a specified frequency and gives engineers an idea of how the design will respond to different types of dynamic loads $[5,6]$.

In this study, $\mathrm{i}$ offer a modelling of flake defects. This defects are modelled by any forms, the length of defects $L c=1 \mathrm{~mm}$, and in the height of wear has been studied for three cases: $\mathrm{VB}=0.1 ; 0.2$ and 0.3 $\mathrm{mm}$. This modelling accomplished by the method of finished elements and with the aid of calculation code ANSYS V15.

\section{Simulation Method}

After the creation of the geometric models from the data dimension, once the geometries are in place, the modal analysis can be started.

\section{Model of cutting tool}

Figure 2 is the model of cutting tool that is designed by using the

*Corresponding author: Aouad Razika, Faculty of Technology Sciences University of Brothers Mentouri Constantine, Algeria, E-mail: aouadrazika@yahoo.fr

Received May 14, 2018; Accepted June 20, 2018; Published June 30, 2018

Citation: Razika A, Idriss A (2018) Frequency Analysis of the Tool with and without Wear during Turning by Modal Analysis. J Material Sci Eng 7: 462. doi: 10.4172/2169-0022.1000462

Copyright: (C) 2018 Razika A, et al. This is an open-access article distributed under the terms of the Creative Commons Attribution License, which permits unrestricted use, distribution, and reproduction in any medium, provided the original author and source are credited. 
solid works software then imported to ANSYS finite element code. The tests were carried out on the cutting tool which was separated into two parts: Cutting insert used has a square shape of $12 \mathrm{~mm}$, and $4 \mathrm{~mm}$

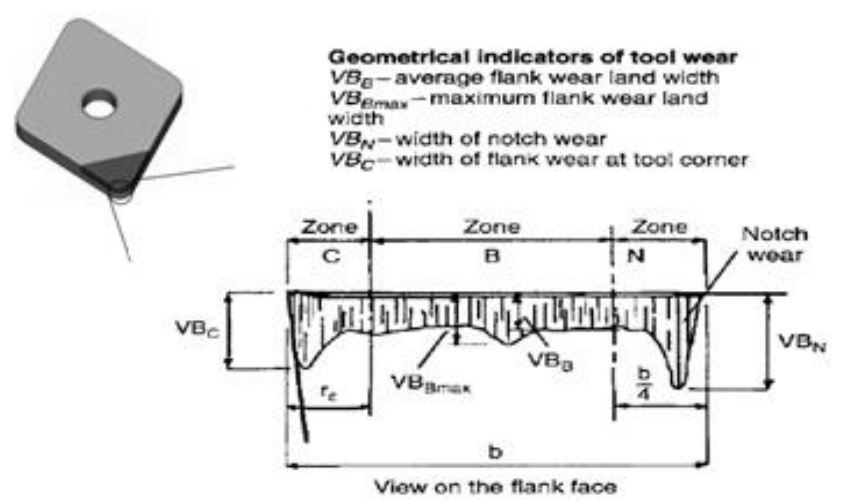

Figure 1: Modèle d'usure typique selon ISO 3685 [3].

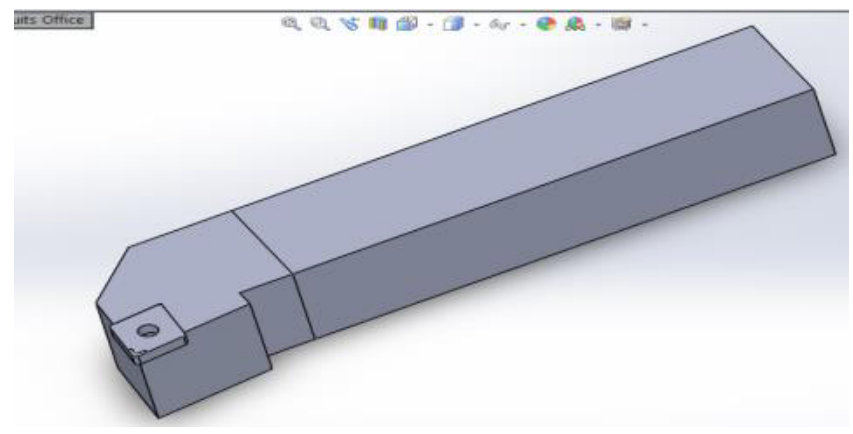

Figure 2: Modelling of cutting tool.

\begin{tabular}{|l|c|}
\hline The mechanical and physical properties & Tool WC \\
\hline Young's modulus, $\mathrm{E}(\mathrm{Pa})$ & $600^{*} \mathrm{e} 9$ \\
\hline Density $\rho\left(\mathrm{kg} / \mathrm{m}^{3}\right)$ & 15000 \\
\hline Poisson's Ratio $\mathrm{v}$ & 0.28 \\
\hline Specific heat $\mathrm{Cp}\left(\mathrm{J} \mathrm{kg}^{-1} /{ }^{\circ} \mathrm{C}\right)$ & 475 \\
\hline
\end{tabular}

Table 1: The mechanical and physical properties of materials used. height with a nose radius fixed at $0.1 \mathrm{~mm}$ on a cutting insert holder is PSBNR 25X25 M12, and the cutting tool and the cutting tool material used is tungsten carbide CW.

\section{The material properties}

Material model and material properties play an important role in the result of the in the Study the vibration. The mechanical and physical properties of used materials in this analysis are shown in Table 1.

\section{Creation of defects}

In the Figure 3a, two cutting inserts are represented: the first is new, while on the second with defect (wear) on the flank surface were created. The dimensions of these defects are: the maximum height VB $\max =0.3 ; 0.2$ and $0.1 \mathrm{~mm}$ with the length of defects $\mathrm{Lc}=1 \mathrm{~mm}$. Then, the deformation modes have been modelled with ANSYS taking into account the various defects created.

\section{Meshing}

Figure $3 \mathrm{~b}$ show the meshing that is done to the cutting tool for vibration analysis. In this analysis mesh generation is auto generated by the ANSYS software, after that, $1 \mathrm{~mm}$ sizing was given to the cutting insert and $10 \mathrm{~mm}$ to cutting insert holder, then we controlled the mesh by the hexahedral dominant method with the type the mesh in Quadrilaterals/Triangular elements which can be used for irregular shapes without much loss of accuracy. The FEM model contains 5251 nodes and 1114 elements.

\section{Loading}

Figure 4 represent the applying the constraint and force loading to the cutting tool. The tool is recessed by three bolts tightening in the tool holder and we represented it by the fixed support. We applied an equivalent force on the nose radius equals $346.41 \mathrm{~N}$, without forgetting that the cutting tool cantilever was limited to $25 \mathrm{~mm}$.

\section{Results and Discussions}

Results from modal analysis are written to the structural results file. Results consist of natural frequency, mode shapes relative stress and force distribution. Those results wish to see, database must contain the same modal for which the solution was calculated.

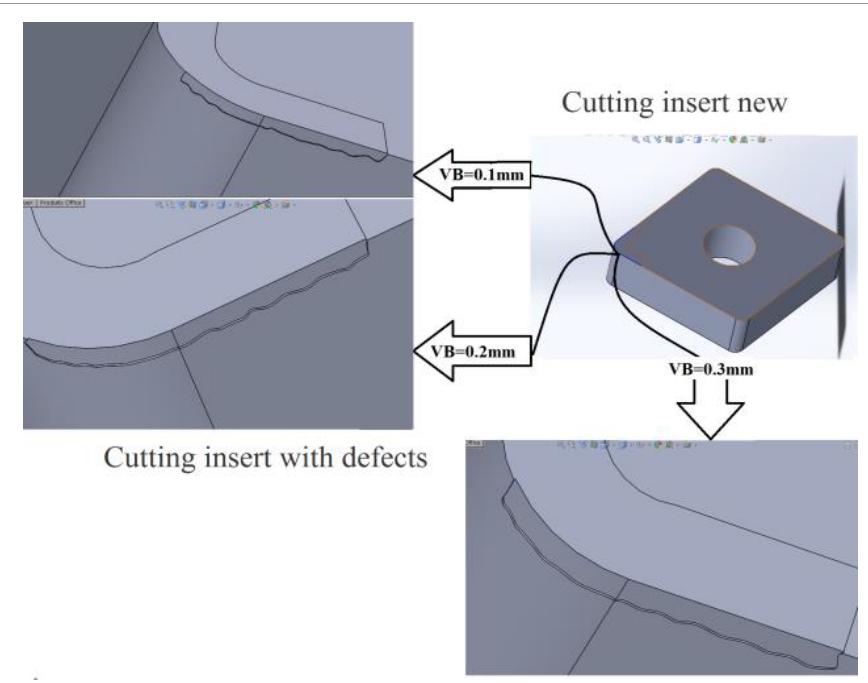

Figure 3a: Different defects created on the flank surface. 


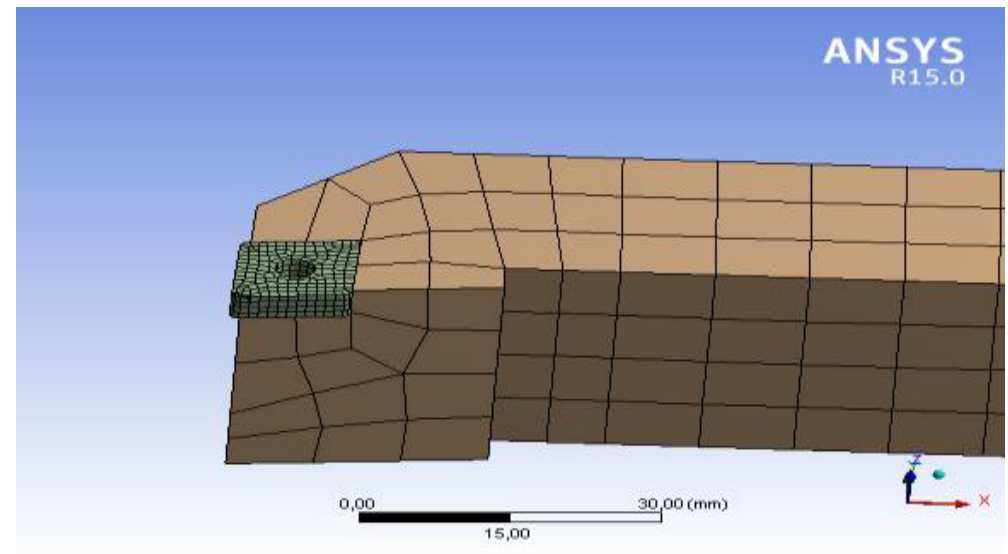

Figure 3b: The mesh model.
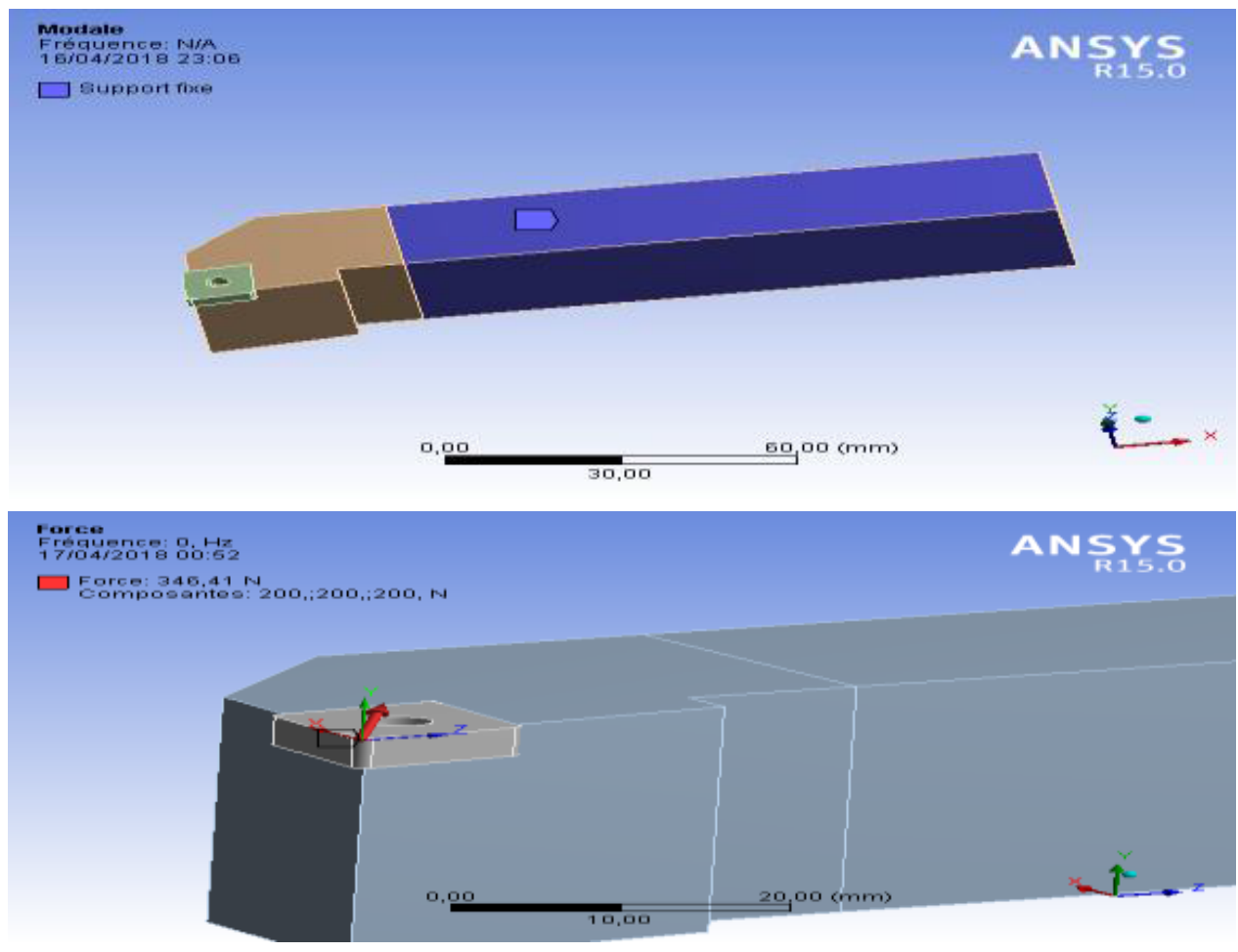

Figure 4: Boundary conditions and force loading.

\section{Modal analysis of finite element models and its natural frequencies analyzing}

Analysis of natural frequencies and mode shapes of FEM are presented from Figures 5 and 6.

Figure $5 \mathrm{a}-5 \mathrm{c}$ represents the comparison of the six mode shapes of FEM with varying defects created in the cutting tool. The frequencies that are obtained at different modes are shown. Similarly deformation at that particular mode is shown by the bar with different colours. We note the red colour indicates the deformation maximum and blue colour indicates deformation minimum. The first six natural frequencies and the corresponding mode shapes were computed by Ansys and are found in Table 2.

The first mode shape $\mathrm{f} 1=337.77 \mathrm{~Hz}$ is the movement of the tool horizontally, corresponding to the $\mathrm{X}$ axes and also represented the error of two perpendicularity surface (surface of the work piece and the tool) in the horizontal plane. But in the cutting tools with defect, we note that the frequency increases with the fault height.

Figure 6 represent the difference between the natural frequencies of the cutting tool for the varying defects created by ANSYS. We note that the frequencies increases with increasing the height of wear who created $(\mathrm{VB}=0.1-0.2$ and $0.3 \mathrm{~mm})$. This increase in the frequencies is explained by the existence of vibration at the contact level. We can say that when the body is light, automatically we get a high frequency as shown in Figure 6.

\section{Harmonic response analysis}

It is a technique utilised to determine the steady state response of 
Citation: Razika A, Idriss A (2018) Frequency Analysis of the Tool with and without Wear during Turning by Modal Analysis. J Material Sci Eng 7: 462. doi: $10.4172 / 2169-0022.1000462$
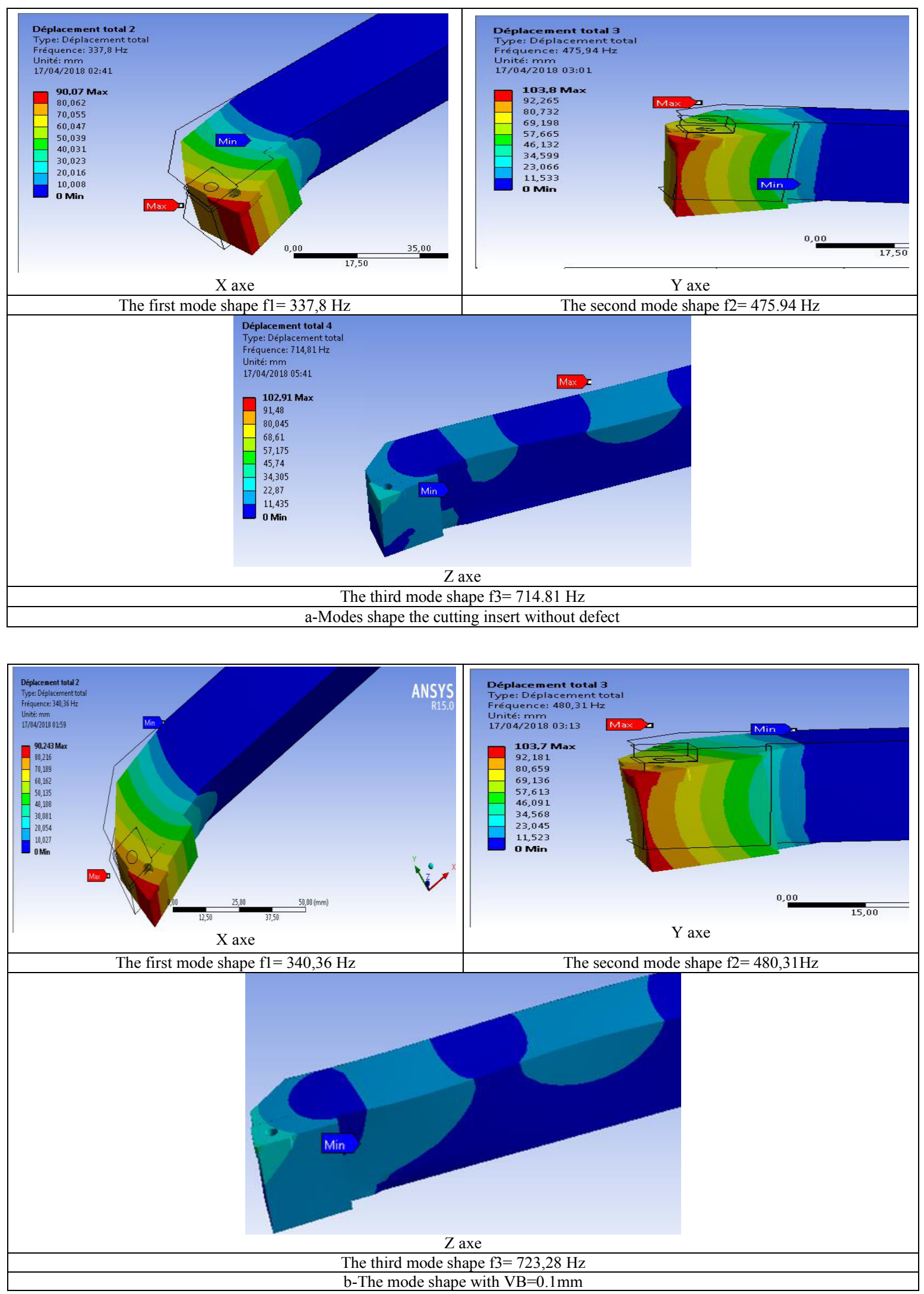
Citation: Razika A, Idriss A (2018) Frequency Analysis of the Tool with and without Wear during Turning by Modal Analysis. J Material Sci Eng 7: 462. doi: $10.4172 / 2169-0022.1000462$

Page 5 of 7
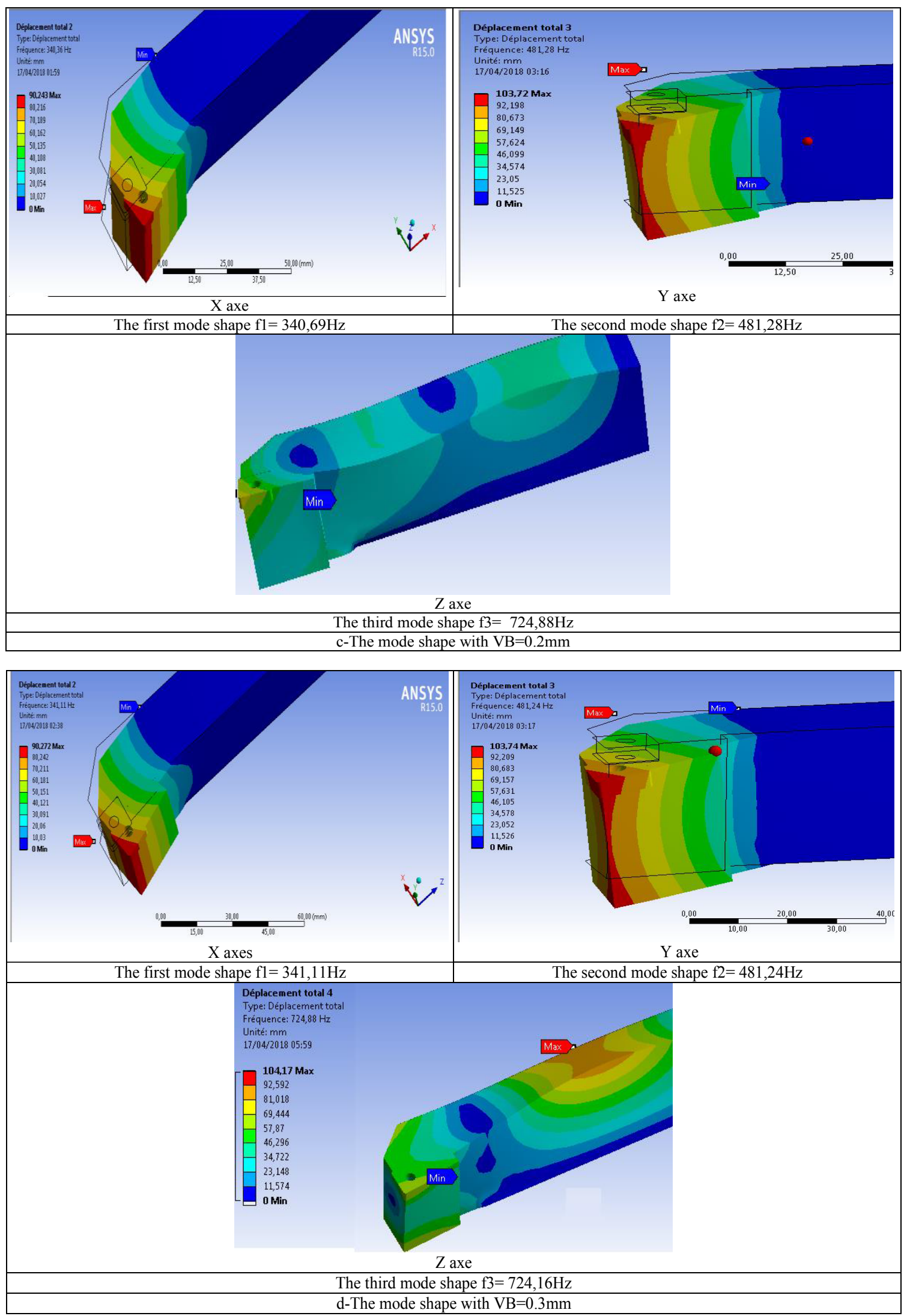

Figure 5: Mode shape the varying defects created with: (a) without defect, (b) VB=0.1 mm, (c) VB=0.2 mm, $d-V B=0.3 \mathrm{~mm}$. 
Citation: Razika A, Idriss A (2018) Frequency Analysis of the Tool with and without Wear during Turning by Modal Analysis. J Material Sci Eng 7: 462. doi: $10.4172 / 2169-0022.1000462$

Page 6 of 7

a linear structure to loads that varies sinusoidal with time. The mode superposition method calculations factored mode shapes (eigenvectors) from modal analysis to calculate the structures response. Hence it is known as harmonic response analysis.

Analysis of deformation in turning heat by finite element method: The analysis results are shown in Table 3 which contains data about tool deformation in individual axes (axe X) and the overall deformation.

Figure 7 represent the comparison of the normal elastic deformation (X axis) simulated by ANSYS with the various defects created. We find that the deformation by tool without defect generates an maximum normal elastic deformation $0.014976 \mathrm{~mm} / \mathrm{mm}$. We note that the

\begin{tabular}{|c|c|c|c|c|}
\hline \multirow[t]{2}{*}{ Mode } & \multicolumn{4}{|c|}{ Natural frequencies for cutting tool } \\
\hline & No. 1 without defect (new) & No. 2 with VB=0.1 mm & No. 3 with VB=0.1 mm & No. 4 with VB=0.1 mm \\
\hline 1 & 337.77 & 340.36 & 340.69 & 341.11 \\
\hline 2 & 475.92 & 480.31 & 481.28 & 481.24 \\
\hline 3 & 714.73 & 723.28 & 724.88 & 724.16 \\
\hline 4 & 987.94 & 994.26 & 995.32 & 995.85 \\
\hline 5 & 1259.7 & 1268.5 & 1270.1 & 1269.9 \\
\hline 6 & 1286.3 & 1290.6 & 1292.7 & 1292.8 \\
\hline
\end{tabular}

Table 2: Natural frequencies from modal analysis of finite element models in ANSYS (Hz).

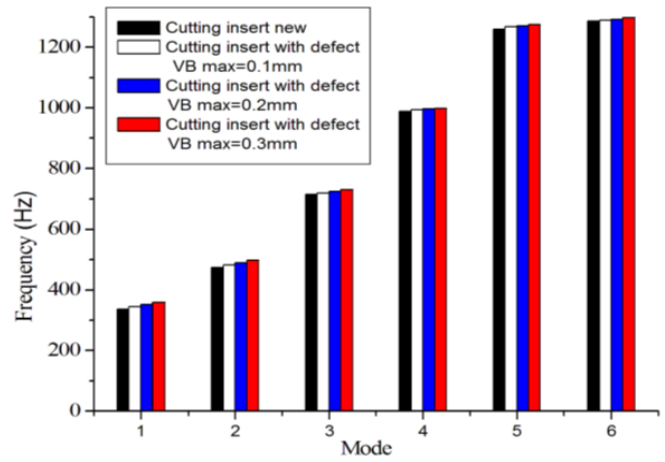

Figure 6: Natural frequencies of the cutting tool the varying defects created.

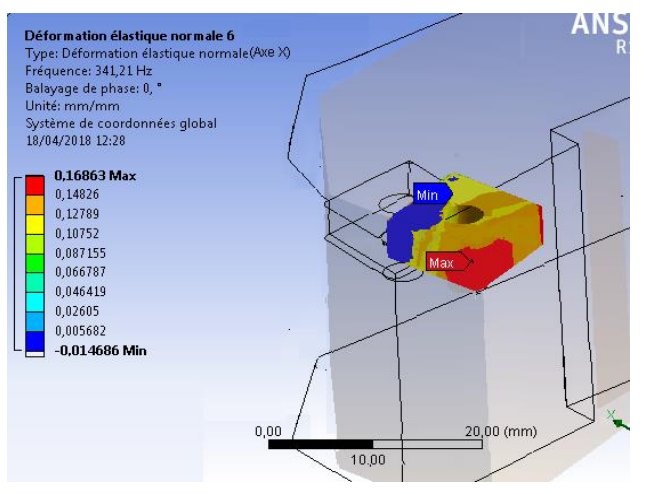

b) Cutting tools with defect $\mathrm{VB}=0.1 \mathrm{~mm}$

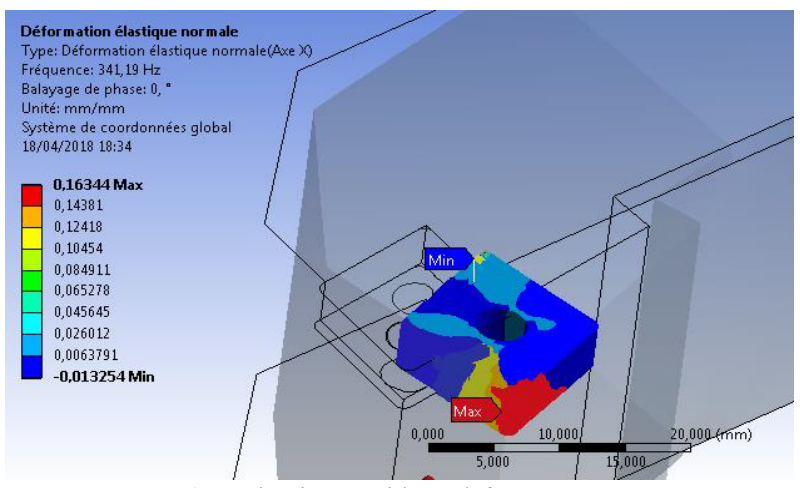

a) Cutting insert without defect

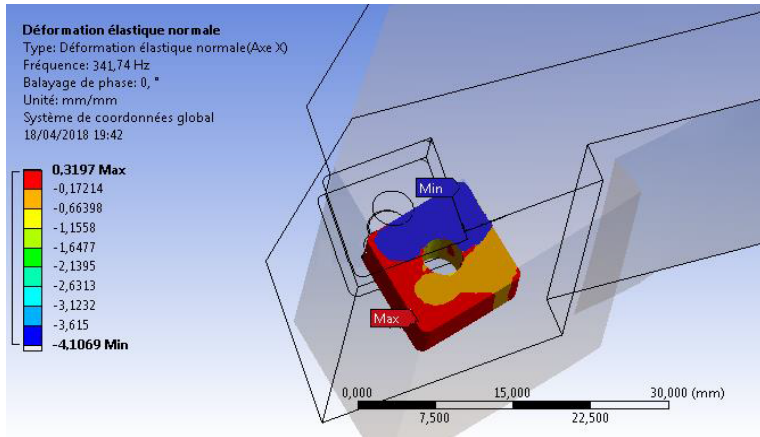

c) Cutting tools with defect $\mathrm{VB}=0.2 \mathrm{~mm}$

Figure 7: Normal elastic deformation ( $X$ axis) for cutting tools: a) without defect, b) with defect $V B=0.1 \mathrm{~mm} \mathrm{c}$ ) VB=0.2 $\mathrm{mm}$. 
Citation: Razika A, Idriss A (2018) Frequency Analysis of the Tool with and without Wear during Turning by Modal Analysis. J Material Sci Eng 7: 462. doi: $10.4172 / 2169-0022.1000462$

Page 7 of 7

\begin{tabular}{|c|c|c|}
\hline $\begin{array}{c}\text { Normal elastic deformation } \\
\text { (Directional Deformation X) }\end{array}$ & Cutting insert without defect & $\begin{array}{c}\text { Cutting insert with defect } \\
\text { VB=0.1 } \mathbf{m m}\end{array}$ \\
\hline Minimum [mm/mm] & -0.16971 & -0.0132 \\
\hline Maximum [mm/mm] & 0.014976 & -0.01468 \\
\hline
\end{tabular}

Table 3: Results of finite element analysis.

deformation by tool new (without defect) generates an maximum normal elastic deformation $0.014976 \mathrm{~mm} / \mathrm{mm}$, while the deformation by tools with defects produces a variable deformation with the height of the defect: for defects $\mathrm{VB}=0.1 \mathrm{~mm}$ and $\mathrm{VB}=0.2 \mathrm{~mm}$, the maximum normal elastic deformation increases in the order of $0.148 \mathrm{~mm} / \mathrm{mm}$, and $0.16 \mathrm{~mm} / \mathrm{mm}$ respectively.

\section{Conclusion}

According to this study, the following conclusions are drawn: Graphs show frequency variations for the different heights of wear who created, these are three cases: $\mathrm{VB}=0.1 ; 0.2$ and $0.3 \mathrm{~mm}$ that are obtained from the vibration analysis. From the graphs it is observed that for $\mathrm{VB}=0.3 \mathrm{~mm}$ has high frequency during the machining compared to $\mathrm{VB}=0.2$ and $0.3 \mathrm{~mm}$. The focus should be on choosing an appropriate combination of cutting parameters (cutting speed, cutting advance, cutting depth, temperature...). According to the readings, these parameters have a significant impact on the degradation of the cutting tool. As well to avoid the effect of vibration on the cutting tool. Mainly the surface after wear becomes a rough surface. From here we can say, the frequencies increases with increasing the height of wear who created $(\mathrm{VB}=0.1-0.2$ and $0.3 \mathrm{~mm})$. In the comparison of the normal elastic deformation of cutting tool in orthogonal direction (axe $\mathrm{X}$ ) simulated by ANSYS with the varying defects created. We note that the analysis of the occurrence of cutting inserts.

\section{References}

1. Rad JS, Zhang Y, Aghazadeh F, Chen ZC (2014) A study on tool wea monitoring using time-frequency transformation techniques. In Innovative Design and Manufacturing (ICIDM), Proceedings of the 2014 International Conference on IEEE, pp: 342-347.

2. Berkani S, Bouzid L, Bensouilah H, Yallese MA, Girardin F, et al. (2015) Modeling and optimization of tool wear and surface roughness in turning of austenitic stainless steel using response surface methodology.

3. Grzesik W (2008) Advanced machining processes of metallic materials: theory, modelling and applications. Elsevier.

4. Pettersson L (2002) Vibrations in metal cutting: measurement, analysis and reduction (Doctoral dissertation, Blekinge Institute of Technology)

5. Ramesha DC, Abhijith KG, Singh A, Raj A, Naik CS (2015) Modal Analysis and Harmonic Response Analysis of a Crankshaft. International Journal of Emerging Technology and Advanced Engineering, pp: 2250-2459.

6. Cristina $\mathrm{P}$, loan T, Viorel M, Alexandru C (2008) Modal analysis of a turning tool system. In Proceedings of the 1st WSEAS international conference on Visualization, imaging and simulation. World Scientific and Engineering Academy and Society (WSEAS), pp: 161-166. 